\title{
Oportunidades educacionais no contexto imigratório e de refúgio: considerações sobre a Alemanha
}

\author{
Priscila Lopes de Godoy ${ }^{1}$
}

Ana Elisa Spaolonzi Queiroz Assis ${ }^{2}$

\section{Resumo}

Este trabalho objetiva discutir a educação na Alemanha no contexto imigratório, diante do desafio de prover oportunidades iguais. Por meio da pesquisa bibliográfica, procedemos com uma leitura do direito internacional sobre os conceitos de nacional, migrante e refugiado. Buscamos, ainda, a compreensão do direito de ingresso e recuperamos a memória dos conflitos desencadeados pela Primavera Árabe e os desacordos e resoluções da União Europeia. Por fim, verificamos os esforços da Alemanha voltados ao sucesso escolar dos migrantes e o seu objetivo de prover oportunidades iguais, concluindo que não somente a aquisição do idioma é suficiente para melhorar o desempenho educacional.

Palavras-chave: Alemanha Refugiados; Direito Internacional Imigração; Crise de Refugiados; Educação e Imigração.

\section{Egalitarian education opportunities in refuge and immigration context: considerations about Germany}

\section{Abstract}

This article aims to discuss the education in Germany in the migration context facing the challenge to promote egalitarian opportunities. Through a bibliographic research we proceeded to a comprehension of international rights about the concepts of national, migrant and refugee. Furthermore, we aim to comprehend the right of entrance hence we recovered the conflicts from Arab Spring and the disagreements and resolutions from the European Union. At last, we verified the efforts from Germany to obtain the migrants school success and the intention to promote egalitarian opportunities. We conclude that only language skills are not enough to improve schools results.

Keywords: Germany Refugees; International Immigration Rights; Refugees Crisis; Education and Immigration.

\section{Introdução}

Para o direito internacional, os conceitos de nacional, migrante e refugiado, além de diferirem, representam limites ao ingresso e circulação entre países. O nacional, aquele que tem a garantia de adentrar o Estado, sendo vedado este impedimento, goza de proteção diplomática quando está no exterior. Já o migrante possui a garantia de deixar o seu país e, em razão de sua nacionalidade, de regressar. Porém, na categoria de migrante, o direito de ingresso é limitado a regras próprias de cada Estado, alguns com regulamentações, outros com arbitrariedades. Já o

\footnotetext{
${ }^{1}$ Universidade Estadual de Campinas, Campinas. Endereço eletrônico: prisdegodoy@gmail.com

${ }^{2}$ Universidade Estadual de Campinas. Campinas. Endereço eletrônico: anasqa@unicamp.br
} 
refugiado, por sua condição vulnerável, deve ter o seu direito de ingresso no exterior assegurado, conforme disposto nos tratados sobre direitos humanos.

Recentemente, em razão da Crise de Refugiados (2015 - 2016), muitos dos que fugiam dos conflitos desencadeados pela Primavera Árabe tiveram o seu direito de ingresso restringido na Europa, o que provocou acalorados debates dentro do bloco. A Alemanha seguiu em defesa do "espírito de comunidade europeia", reclamando por ações conjuntas, como o estabelecimento de cotas de ingresso, propondo-se a receber os refugiados e facilitar o acesso à educação e integração social.

Partimos do sistema educacional alemão e das lacunas por ele deixadas para traçar algumas considerações a respeito das oportunidades educacionais na Alemanha, as quais vêm sendo sinalizadas há mais de uma década por organismos multilaterais como Unicef e OCDE através dos resultados do Pisa.

Com o objetivo de desvelar as dificuldades de se prover oportunidades educacionais igualitárias às crianças oriundas de contexto migratório e de refugio na Alemanha, traçamos um percurso de pesquisa que partiu da compreensão do direito internacional sobre os conceitos de nacional, imigrante e refugiado. Para tanto, apoiamo-nos em Vedovato (2013) e Ramos (2011).

Fizemos também uma análise documental dos tratados sobre direitos humanos, como a Declaração Universal dos Direitos Humanos (ONU, 1948) e a Convenção sobre os Direitos da criança (UNICEF, 1989). Consultamos a legislação alemã, mais especificamente, o Código Social /Sozialgesetzbuch e as alterações que deram origem à lei que corresponde ao Estatuto da Criança e do Adolescente /Kinder - und Jugendhilfegestz (ALEMANHA, 1990), além de documentos e relatórios de orientações supranacionais como em Overview of Child Well Being in Germany: Policy towards a Supportive Environment for Children (BERTRAM, 2006); Key Data on Early Childhood Education and Care in Europe (EUROPEAN COMISSION /EACEA/ EUROSTAT, 2014); Unicef Report on the Situation of Children in Germany (SCHNEIDER, 2008).

Ainda no que concerne aos procedimentos metodológicos, para compreender melhor a crise dos refugiados na União Europeia, concentramo-nos na dissertação de mestrado de Rijo (2017), intitulada A União Europeia face à crise dos migrantes e refugiados: um ator dividido sob escrutínio e o diálogo com a educação na Alemanha delineou-se através da pesquisa desenvolvida por uma das autoras, a fim de concluir o curso de pedagogia, intitulada As políticas 
para a educação infantil no Brasil e Alemanha: reflexões a partir do diálogo com as políticas emanadas pelos organismos multilaterais (GODOY, 2017).

No âmbito discursivo, organizamos o trabalho com o seguinte traçado: primeiro apresentamos uma leitura conceitual do direito internacional sobre os termos nacional, migrante e refugiado, e nos colocamos do lado de uma postura de defesa dos direitos humanos no ingresso ao país estrangeiro, tal qual Vedovato (2013). Depois, concentramo-nos no problema da intensificação de fluxos migratórios em direção à Europa, resultantes dos conflitos oriundos da Primavera Árabe e as discussões no âmbito da União Europeia. Finalizamos com considerações a respeito do direito à educação e oportunidades de vida no contexto migratório.

Embora o trabalho focalize questões intrinsecamente europeias e alemãs, a relevância do tema centra-se no direito humano de salvaguarda da vida e na compreensão da educação como forma de se promover oportunidades igualitárias.

\section{Nacional, migrante e refugiado}

Neste trabalho, que se propõe à reflexão sobre as oportunidades educacionais do migrante na Alemanha, seja no contexto de refúgio ou de qualquer outra motivação imigratória, considerando o contexto da crise dos refugiados que teve o seu apogeu entre 2015 e 2016, fazse, primeiramente, necessária a compreensão da diferença e das relações entre os conceitos de nacionalidade, migração e refúgio, sobre os quais nos apoiamos em Vedovato (2013) e Ramos (2011), respectivamente.

A nacionalidade, um vínculo jurídico que, segundo Vedovato (2013), é base para atuações legais e sociais internas, medeia os direitos e obrigações do indivíduo com o Estado, sendo que o seu conceito está intrinsecamente relacionado aos dispositivos normativos sobre a circulação de não nacionais e a permeabilidade das fronteiras. O nacional não pode ser barrado na fronteira, nem o seu ingresso pode ser impedido, visto que ele está amparado pelas regras definidoras da nacionalidade (VEDOVATO, 2013).

Mediante a nacionalidade, o Estado delimita o âmbito de sua competência pessoal sobre uma população de indivíduos permanentes e estáveis em seu território e também fora dele, tanto em áreas que façam parte de outro 
território, na sua competência extraterritorial, quanto em regiões de domínio público internacional, como o alto-mar e partes da Antártica (VEDOVATO, 2013, n.p).

Portanto, essas pessoas, migrantes que se lançam para além das fronteiras nacionais, mesmo ao se estabelecerem em outro país, possuem, graças a sua nacionalidade, o direito de receber proteção diplomática. Outro direito, o de deixar o território do Estado, teve o seu reconhecimento após a Segunda Guerra Mundial, com a Carta das Nações Unidas (1945) e a Declaração Universal dos Direitos Humanos (1948), sem que um dilema maior fosse enfrentado: o direito de ingresso do estrangeiro em outros territórios (VEDOVATO, 2013).

Sabe-se que os deslocamentos individuais, em grupo ou populacionais não é fato recente na história mundial. Desde os tempos mais remotos, os povos nômades se deslocavam em busca de alimentos e, mesmo ao se estabelecer o modo de vida sedentário, as trocas comerciais na região do mediterrâneo ocorriam em caráter ordinário. As invasões bárbaras, bem como a fuga de regiões conflituosas ou em situação de guerra, também deram propulsão aos deslocamentos. Outras razões, como a busca por condições de uma vida melhor, ainda promovem deslocamentos, que, curiosamente, não têm se restringido às famigeradas rotas do eixo sul para o norte, mas também têm ocorrido em direção a países emergentes de economias proeminentes no eixo sul-sul.

Conforme as condições e razões pelas quais cada um ingressa para viver num país estrangeiro, essas pessoas são categorizadas em imigrantes ou refugiados. De acordo com Portela e Schwinn (2018, p.702-703), estes se diferenciam no ordenamento jurídico, de modo que os "migrantes são tratados pela legislação nacional. Refugiados, por possuírem salvaguardas legais específicas, são tratados de acordo com critérios e normas internacionais". Ainda segundo as autoras, os refugiados são aqueles que cruzam fronteiras internacionais, buscando escapar de situações de conflito que violam os direitos humanos em busca de segurança e para preservar a própria vida. Assim, "todo refugiado é um migrante, mas nem todo migrante é um refugiado" (PORTELA; SCHWINN, 2018, p.702).

Quando se analisam as migrações no cenário mundial, deve-se levar em conta que estas não são fatos inéditos na história, isto é, pessoas sempre se deslocaram motivadas, a partir dos condicionantes endógenos, como por 


\begin{abstract}
exemplo as crises econômicas, perseguições políticas e religiosas, guerras e catástrofes ambientais, e também a partir de condicionantes exógenos, como por exemplo, qualidade de vida, educação, oportunidades laborais, etc. As formas de recepção e acolhimento destas populações pelos estados variam de acordo com as políticas discricionárias, onde, concomitantemente, assiste-se a um processo de assimilação e outro de segregação, onde a subjetividade e a vulnerabilidade do ser imigrante é flagrantemente exposta (PORTELA; SCHWINN, 2018, p.703).
\end{abstract}

Ramos (2011) traça um panorama histórico, pelo qual atravessou o Direito Internacional na construção do conceito de refugiado. Segundo ele, até a chegada do século XX não havia regras claras sobre situações que demandavam refúgio, por isso, era com base nas leis nacionais que se decidiam sobre a concessão de abrigo. "O tratamento dado aos refugiados dependia, então, da generosidade (ou não) das leis nacionais, em especial aquelas relativas à concessão de asilo" (RAMOS, 2011, p.24-25).

Com o estabelecimento da Sociedade das Nações, em 1919 é que houve, segundo o autor (RAMOS, 2011), uma discussão sobre o tratamento a ser dado aos refugiados, o que ocorreu em razão da Revolução Russa e das crises no antigo Império Otomano. Porém, ele aponta que o marco legal veio apenas em 1948, com a Declaração Universal dos Direitos Humanos, a qual previu o direito de se procurar asilos em outros países, diante de casos de perseguições. Em 1951, na Convenção de Genebra, aprovou-se o Estatuto dos Refugiados, não só abordando seus direitos e deveres básicos, como também restringindo a condição de refugiado àqueles cujos fluxos migratórios ocorreram antes de 1951. Além disso, Ramos (2011) observa que os Estados poderiam aplicar uma restrição geográfica, como, por exemplo, a Europa poderia aplicar o Estatuto dos Refugiados apenas aos seus pares.

A mencionada restrição temporal foi banida somente em 1967, com o Protocolo Adicional à Convenção sobre Refugiados. A partir de então, a compreensão sobre o conceito de refugiado passou por ampliações sequenciais, como sistematiza Ramos (2011): 1) em 1974, a Convenção da Organização da Unidade Africana considerou refugiado aquele que em um cenário de graves violações dos direitos humanos deixou a residência e buscou refúgio em outro Estado; 2) em 1984, a Declaração de Cartagena acrescentou que refugiados são também pessoas que fugiram de seus países, pois a vida, a segurança ou liberdade foram ameaçados pela violência generalizada, pela agressão estrangeira, por conflitos internos, pela violação 
maciça dos direitos humanos ou outras circunstâncias que tenham perturbado gravemente a ordem pública.

Vedovato (2013) trata do direito de ingresso no estrangeiro como uma questão humanitária não apenas em casos de refúgio, mas também como um direito que não pode ser recusado sem fundamentação ou de maneira arbitrária, visto que, com a ratificação da Declaração de Direitos Humanos, as nações selaram um acordo supranacional que deve ser respeitado. Destarte, todos os cuidados devem ser tomados para se evitar distorções na obtenção da permissão de entrada.

\footnotetext{
O que se pode asseverar, de início, é que a regulação da migração reflete, em cada país, a opinião pública e a atitude política em relação ao estrangeiro. Em alguns Estados, ela é complexa e suas peças nem sempre se encaixam bem, podendo mudar constantemente; em outros, há uma regulação razoável, com clara normatização que se mantém por longos períodos (VEDOVATO, 2013, n.p).
}

Como o seu objetivo é discutir o direito do ingresso de uma maneira geral, isto é, não apenas em casos de refúgio, o autor define migrante todo aquele que deixa o seu Estado para ingressar em outro. Fugindo da utopia de um mundo sem fronteiras, ele defende que a nacionalidade não pode ser razão de impedimento da entrada em outro país e reclama pela universalidade dos direitos humanos como fundamento para a circulação das pessoas mundo afora.

Para tanto, deve haver, segundo o autor, uma teoria para o controle das decisões estatais, que não permita ignorar os direitos humanos, tampouco negar vistos de estudos e de trabalho, que, por sua natureza, já são justificáveis. Vedovato (2013) parte para a defesa de que deve ser estabelecido um fundamento jurídico, a fim de evitar limitações de entrada conduzidas pelo humor estatal.

Voltando-nos ao contexto local deste trabalho, a problemática da recusa de ingresso foi exacerbada no período de 2014 a 2016, na conhecida "Crise dos Refugiados", em que a busca de abrigo em países membros da União Europeia, abalou as estruturas do bloco quando se escancararam as divergências sobre a concessão de refúgio àqueles que se arriscavam por terra e mar na fuga da Guerra Síria e de outros países árabes em conflitos internos. 
No caso dos refugiados sírios, apesar da explícita situação de calamidade desta população, vitimada por um conflito que já dura mais de seis anos, e de, segundo Salomão (2017), a União Europeia contar com um sistema jurídico próprio e supranacional para regulamentar as ações estatais, houve, por parte de alguns países, o endurecimento de um lado conservador que fez fortalecer posicionamentos eurocéticos, quando entrou em debate a concessão de refúgio e abertura das fronteiras. Diante desse dilema, a Alemanha ocupou um papel central que será relembrado a seguir.

\section{Primavera árabe, guerra Síria e refúgio}

A guerra na Síria iniciou-se como um dos desdobramentos da chamada Primavera Árabe, um movimento insurgente contra o abuso de poder, que teve início na Tunísia, em 2010, em forma de protestos contra a corrupção policial e a indiferença governamental. Esse foi o primeiro passo para que a contestação de regimes autocráticos se espalhasse pelo Médio Oriente e Norte da África, resultando no fim de regimes autoritários na Tunísia, Líbia e Egito (RIJO, 2017). Na Síria, entretanto, Bashar Al-Assad respondeu aos insurgentes com violência extrema, gerando um conflito que destruiu o país, transformou-se em guerra civil e diariamente ceifa vidas de civis em um palco de disputas dicotômicas entre potências como Estados Unidos e Rússia.

Rijo (2017) observa, em sua dissertação de mestrado, apresentada à Universidade do Minho, que no interstício de 2015 a 2016, como a instabilidade na região do Médio Oriente e do Norte da África não apresentou sinais de recuperação, os fluxos migratórios intensificaram-se tanto em sua própria região quanto em direção à Europa e, do ano de 2015 a 2016, houve um aumento constante de requerentes de asilo.

As discussões ocorreram na Comissão Europeia em um momento tardio, pois o caos já havia se instaurado. A reação dos membros do bloco foi de um extremo a outro: do acolhimento até o fechamento da fronteira e o endurecimento de uma política conservadora e eurocética, que culminou no Brexit, isto é, na decisão do Reino Unido de deixar a União Europeia. Uma das razões para o desacordo dentro do bloco foi "a constante relutância dos Estados Membros em delegar a sua soberania nacional a favor da vertente comunitária" (RIJO, 2017, p.159).

Entre 2011 e 2014, segundo Rijo (2017), a crise migratória ainda não havia atingido o seu 
auge na Europa, portanto, Reino Unido e Alemanha adotavam entre si uma postura amistosa e confluente em relação ao conflito, responsabilizando-se por oferecer apoio e suporte financeiro aos países da região que recebia a grande maioria dos refugiados.

Rijo (2017) mostra que, a princípio, houve uma aproximação de ideias entre estes Estados, não havia incômodo em enviar dinheiro para que cada qual se mantivesse em sua região, enquanto a Síria era destruída. Mas, posteriormente, ocorre um distanciamento das posições políticas alemãs e inglesas,

À semelhança do observável na abordagem britânica, a posição alemã é inicialmente restrita a um apoio financeiro e apelos a uma intervenção internacional, sendo constantemente afastada uma eventual política de acolhimento. No entanto, é possível, no decorrer do período, observar uma alteração de postura, com a Alemanha a assumir gradualmente uma postura de abertura ao acolhimento (RIJO, 2017, p.112).

De acordo com Rijo (2017), entre 2015 e 2016, vendo que a instabilidade nas regiões conflituosas não mostrava sinais de atenuação e, em decorrência disso, os fluxos migratórios em direção à Europa intensificavam-se, a chanceler alemã, Angela Merkel passa a defender o acolhimento dos refugiados nos territórios da União Europeia. Ela abriu as portas da Alemanha e, mesmo com as críticas que recebeu dos membros do próprio partido, manteve-se firme no propósito humanitário de oferecer refúgio àqueles que solicitavam, apelando também pela distribuição equitativa dos refugiados. A fim de garantir a estabilidade dos países fronteiriços, invocou constantemente o princípio de uma Europa coesa e unida. Porém, a chanceler teve de se deparar com muitas resistências:

Os efeitos da crise migratória são bastante críticos, com o seu prolongar e a percecionada ineficácia das autoridades nacionais e europeias, as sociedades europeias veem-se agora com um crescente euroceticismo e fortalecimento das forças políticas de extrema-direita em vários países da UE (Dinamarca, Holanda, França, Reino Unido) o que leva os governos nacionais a adotarem medidas mais conservadoras e nacionalistas, salvaguardando os seus interesses, o que coloca em causa a possibilidade de encontrar uma resposta europeia coesa e eficaz para enfrentar o desafio. Os atentados de 13 de Novembro de 2015 em Paris, França, enfatizam ainda mais os medos da população europeia, com as forças de extrema-direita a catapultarem a sua relevância e a levarem os governos nacionais a endurecerem as suas posições (RIJO, 2017, p.117). 
Ainda enfrentando divergências, Merkel defendeu uma política de cotas para distribuição de refugiados, o que, segundo Salomão (2017, p.208), tornaria inválido o Sistema Dublin, o qual “impõe a regra de análise do pedido de refúgio no Estado em que o indivíduo chegou na primeira ocasião", por outro lado, tal medida desoneraria países fronteiriços como Itália e Grécia do insustentável fardo de receber mais refugiados do que poderia.

\begin{abstract}
O sistema de cotas prescreveria exatamente o contrário, ou seja, ao chegarem os indivíduos ao Estado este seria encaminhado a outro país e será neste que o pedido de refúgio será solicitado. A Comissão Europeia entende que o sistema de cotas auxiliaria na situação urgente em que se encontram países como Grécia e Itália que já receberam 300 mil refugiados vindos do Oriente Médio e África, e as cotas dividiria a responsabilidade da questão dos refugiados com outros países e evitaria o caos (SALOMÃO, 2017, p.208).
\end{abstract}

Como se sabe, não havendo acordo sobre as cotas, a decisão dos membros da União Europeia, mediante o incontrolável ingresso de refugiados, foi fechar um acordo de cooperação com a Turquia, numa tentativa de barrar o fluxo para dentro de seus territórios. Este acordo fez com que os migrantes irregulares que chegassem à Grécia, retornassem à Turquia, "sendo que, por cada pessoa que regressasse, uma seria aceita num Estado Membro com estatuto de refugiado. O acordo recebeu inúmeras críticas por parte do Alto Comissariado das Nações Unidas (ACNUR) e de várias organizações humanitárias", que apontavam para a "debilidade do respeito pelos Direitos Humanos na Turquia" (RIJO, 2017, p.167-168).

Um grave aspecto, com relação dos direitos humanos, ressaltado por Salomão (2017, p.207), foi o seu apontamento de que a crise de refugiados está gerando uma discricionariedade das autoridades europeias, que passam a "determinar 'classificações' sobre a qualidade dos refugiados, visto nas seletivas que barram os refugiados muçulmanos, permitindo a entrada de somente cristãos". Sua observação vai ao encontro da defesa de Vedovato (2013), de que os direitos humanos devem ser respeitados no direito do ingresso ao país estrangeiro, por isso, a religião não pode ser empecilho para se conseguir asilo.

Visto que a Alemanha adotou uma política (embora com recuo posterior) de abrir as suas portas para os refugiados e, sabendo que, apesar de o país adotar uma perspectiva educacional multicultural e inclusiva, avaliações como o PISA têm revelado as disparidades nas oportunidades 
educacionais de jovens de origem alemã e estrangeira. Deste modo, cabe discutir se o acolhimento ao migrante contemplará a efetivação do direito à educação em condições igualitárias.

\section{Frühe chancen: chances precoces e oportunidades iguais?}

A iniciativa de qualquer país de abrir as suas portas para o migrante, gera impactos sociais. Dentre os setores mais sensíveis, está a educação, que, além de um direito social, é um direito humano. Como um direito humano, data de 1948, expresso na Declaração Universal dos Direitos Humanos, em que se estabelece em seu artigo 26, da educação: “§1. Toda pessoa tem direito à instrução. A instrução será gratuita, pelo menos nos graus elementares e fundamentais. A instrução elementar será obrigatória. A instrução técnico-profissional será acessível a todos, bem como a instrução superior, esta baseada no mérito" (ONU, 1948).

Também a Convenção sobre os Direitos da Criança, de 1989, reconhece no artigo 28, primeiro parágrafo, que toda criança tem direito à educação. Estabelece que o ensino primário deve ser obrigatório, gratuito e disponível a todos, com estímulo ao desenvolvimento do ensino secundário em suas diferentes formas (geral e/ou profissionalizante) e objetiva a redução da evasão escolar e a melhoria do acesso ao ensino superior.

Na convenção, a educação infantil é citada apenas no artigo 18, parágrafo 3, onde se determina que os Estados-Parte adotarão medidas para que as crianças, cujos pais trabalham, tenham direito de beneficiar-se dos serviços de assistência social e creches. A associação da educação infantil como assistência social desobriga o Estado de garantir a educação infantil como um direito social da criança.

Entretanto, na Alemanha houve em 1996 e 2013, respectivamente, alterações no livro VIII do Sozialgesetzbuch, a primeira alteração deu direito à vaga a todas as crianças a partir dos três anos de idade; a segunda ampliou este direito para as crianças a partir de um ano de idade. É importante ressaltar a educação infantil como um direito, sendo que esta etapa, circunscrita ao nível elementar na Alemanha, não é compulsória. A obrigatoriedade recai sobre as crianças a partir de seis anos de idade, as quais devem ingress ar na Grundschule (escola primária). Como os governos estaduais têm autonomia para regulamentar localmente 
cada sistema de ensino, pode haver variações nos tempos de duração do nível primário e nas escolas de nível secundário. Ainda assim, as etapas de escolarização e os modelos de escola disponíveis permanecem os mesmos. A escolarização obrigatória divide-se da seguinte maneira:

- $\quad$ Grundschule (escola primária): com duração variável de quatro a seis anos, a depender do estado. Em todo o país, a escola pública obrigatória é gratuita a partir do primeiro ano da Grundschule e a prática de homeschooling não é permitida.

Aqui cabe a abertura de parênteses, a fim de explicitar que, ao concluir o primário, dependendo do desempenho escolar apresentado, as crianças vão ingressar em diferentes estruturas educacionais, tendo a sua formação profissional determinada a partir do nível secundário, em três modelos institucionais:

- Hauptschule: com duração variável de cinco a seis anos, permite a formação para um ofício de trabalho ou para exercer uma atividade na indústria ou agricultura.

- Realschule: com duração de seis anos, permite o ingresso posterior em uma escola de nível técnico.

- Gymnasium: com duração variável de oito a nove anos, permite ao estudante fazer o Abitur, um teste cuja pontuação classifica o estudante no pleito de uma vaga na universidade.

A organização do sistema escolar completa-se com o nível terciário, onde a formação se dá em escolas técnicas (Berufsschule) e universidades (Fachhochschule e Universität) e no nível quaternário (Volkshochschule), que consiste no oferecimento da educação para adultos que não concluíram o nível primário e secundário na idade apropriada.

Desta forma, o sistema educacional alemão organiza-se da seguinte maneira: 
Quadro 1: Níveis de ensino no sistema educacional alemão

\begin{tabular}{|c|c|c|c|c|c|}
\hline \multirow{6}{*}{ Alemanha } & \multicolumn{5}{|c|}{ Níveis de Ensino } \\
\hline & $\begin{array}{c}\text { Nível } \\
\text { Elementar }\end{array}$ & Nível Primário & Nível Secundário & Nível Terciário & Nível Quaternário \\
\hline & $\begin{array}{c}\text { Krippe } \\
\text { (creche) } \\
\text { De } 1 \text { a } 3 \text { anos } \\
\text { de idade }\end{array}$ & \multirow{4}{*}{$\begin{array}{l}\text { Grundschule } \\
\text { (escola } \\
\text { fundamental / } \\
\text { escola } \\
\text { primária) } \\
\text { De } 6 \text { a } 10 \text { anos } \\
\text { de idade }\end{array}$} & $\begin{array}{c}\text { Hauptschule } \\
\text { (escola } \\
\text { secundária geral) } \\
\text { De } 10 \text { a } 15 \text { anos } \\
\text { de idade }\end{array}$ & $\begin{array}{c}\text { Universität } \\
\text { (Universidade) } \\
\text { A partir dos } 19 \\
\text { anos de idade }\end{array}$ & \multirow[t]{4}{*}{$\begin{array}{c}\text { Volkshochschule } \\
\text { (Escola superior } \\
\text { popular / } \\
\text { educação de } \\
\text { jovens e adultos) } \\
\text { Variável }\end{array}$} \\
\hline & & & $\begin{array}{c}\text { Realschule } \\
\text { (Escola } \\
\text { secundária } \\
\text { intermediária) } \\
\text { De } 10 \text { a } 16 \text { anos } \\
\text { de idade }\end{array}$ & & \\
\hline & \multirow[t]{2}{*}{$\begin{array}{l}\text { Kindergarten } \\
\text { (jardim de } \\
\text { infância / pré- } \\
\text { escola) } \\
\text { De } 4 \text { a } 6 \text { anos } \\
\text { de idade }\end{array}$} & & $\begin{array}{c}\text { Gymnasium } \\
\text { (Escola } \\
\text { secundária } \\
\text { superior) } \\
\text { De } 10 \text { a } 19 \text { anos } \\
\text { de idade }\end{array}$ & \multirow[t]{2}{*}{$\begin{array}{c}\text { Hochschule } \\
\text { (Escola superior) } \\
\text { A partir dos } 19 \\
\text { anos de idade }\end{array}$} & \\
\hline & & & $\begin{array}{c}\text { Gesamtschule } \\
\text { (escola integrada } \\
\text { que une a } \\
\text { Realschule ao } \\
\text { Gymnasium). } \\
\text { Variável de } 10 \\
\text { até os } 19 \text { anos } \\
\text { de idade }\end{array}$ & & \\
\hline
\end{tabular}

Fonte: Extraído e adaptado de Godoy (2017)

Como se pode inferir, este sistema de ensino, responsável pela separação de crianças em escolas que vão definir o seu futuro profissional desde muito cedo, é responsável por reduzir as oportunidades educacionais, ao mesmo tempo em que conforma cada qual em seu lugar dentro do modelo de produção capitalista.

Ainda em 2008, o relatório do Fundo das Nações Unidas para Infância (UNICEF), intitulado The situation of children in Germany (2008), de Christian Schneider, sublinha como os aspectos socioeconômicos e o contexto migratório influenciam as oportunidades educacionais na Alemanha. Essa conclusão é dada com base nos resultados do Programme for International Student Assessment (Pisa), os quais associaram o insucesso no exame à formação dos pais e à imigração, afirmando ainda que "as crianças, filhas de famílias estrangeiras, são com menos frequência atendidas na educação infantil em seus primeiros anos de vida [...] 
dentre elas, 17\% quando jovens, abandonam a escola sem o diploma" (SCHNEIDER, 2008,n.p, tradução nossa) $)^{3}$. O relatório defende que a frequência na educação infantil é um meio de superação do problema.

Essas diferenças são resultado de uma política específica de emigração na Alemanha, datada há mais de trinta anos, que teve por objetivo a importação de mão de obra não qualificada para realização de trabalhos subalternos. No momento, a questão central é a integração dessas crianças não descendentes de alemães, especialmente das de origem não europeias, de modo que o sistema escolar possa prover a elas as mesmas oportunidades das crianças alemãs (BERTRAM, 2006, p.16-17, tradução nossa) ${ }^{4}$

De fato, existem muitas reclamações de professores que alegam receber alunos em fase de alfabetização sem que eles sequer saibam o mínimo do idioma alemão. É nesse sentido que a educação infantil para a criança imigrante será defendida nas políticas educacionais do Estado, a fim de que ela, além de socializar-se, possa aprender o idioma nacional. Bertram (2006, p.18, tradução nossa) ${ }^{5}$ sustenta que essas crianças precisam de um ambiente no qual elas tenham a chance de se desenvolverem junto a crianças de sua idade e independente de seus pais, onde a cultura alemã seja acessível e atraente.

Schneider (2008), porém, levanta algumas razões que devem ser consideradas para que

\footnotetext{
${ }^{3}$ Cf. original: "Children from non-German families more rarely attend nursery school in their first years of life [...] approximately $17 \%$ of all youths with a migrant background leave school without a diploma". (SCHNEIDER, 2008, n.p.) ${ }^{4} \mathrm{Cf}$ original: A central question for a child-friendly, sustainable German society is going to be the integration of children of non-German descent, particularly those from a non-European background. According to the PISA findings (OECD 2006), Germany has so far not managed to integrate these children into the school system and provide them with the same opportunities as children from German homes [...]This is the result of a specific immigration policy in Germany that, unlike other countries such as Canada, aimed at bringing workers with a low educational level into the country to do the menial jobs. Clearly, no school system can set right the decisions made 30 years ago (BERTRAM, 2006, p. 16-17). ${ }^{5} \mathrm{Cf}$. original: The process of child development affects the child's whole personality and this split between care, upbringing and education is not a model that lends itself to future planning. This is particularly apparent with children from migrant homes as they need special support because of their tendency to fail at school. In the 1960s, when Dahrendorf and Peisert identified the education gap between rural and urban areas, all federal states invested considerable resources to reduce the gap. We now act as if such educational variance could be resolved through appeals to parents, language testing and perhaps language courses. This strategy sadly reflects the enduring partition of education and upbringing whereby parents should make sure the child is motivated to learn German and the school provides remedial classes. As in the 1960s, the attempt is made to get the parents to understand something that is not necessarily part of their own life experience.

This is why children need dependable environments in which they have the chance to develop independently of their parents and with children of their own age and in which German culture is made accessible in an appealing manner. This is very important in urban centres because of the high concentration of families from a non-German background in some city areas. (BERTRAM, 2006, p. 17-18).
}

Periódico Horizontes - USF - Itatiba, SP - Brasil - e019041 
crianças de contextos migratórios não frequentem a creche ou os jardins de infância:

1) Ambos não são percebidos como instituições de ensino;

2) As considerações financeiras tornam a educação infantil desvantajosa quando outros membros da família estão disponíveis para os cuidados;

3) Receio de uma possível alienação cultural ${ }^{6}$.

Das razões assinaladas, o item número dois traz um importante dado que afasta os filhos de migrantes da educação infantil: na Alemanha, esta etapa educacional não é gratuita, devendo os pais contribuir com no mínimo $14 \%$ de seu salário. Caso não disponha de meios para arcar com este custo, eles devem reclamar subsídio estatal. A chamada taxa parental já foi abolida em alguns estados, como em Hamburgo, Hessen, na Baixa Saxónia, na Renânia do Norte-Vestefália (apenas no último ano antes da entrada na escola), em Berlim (nos três últimos anos do jardim de infância) e na Renânia Palatinado (a partir de dois anos de idade) (EUROPEAN COMMISSION/EACEA/EUROSTAT, 2014, p.84, tradução nossa) $)^{7}$. Se por um lado tais iniciativas configuram-se relevantes para facilitar o acesso à educação infantil, por outro contribui com a desigualdade, já que alguns Estados a custeiam enquanto outros não.

Tradicionalmente, a oferta de vagas na educação infantil ocorre em instituições chamadas de Tageseinrichtung, elas são regulamentadas pelo Sozialgesetzbuch (Código Social), oferecendo atendimento na Krippe (creche) a crianças de zero a três anos e no Kindergarten (pré-escola), para crianças de quatro a seis anos. Existe ainda a Kindertageseinrichtung ou Kindertagesstätte, vulgo Kita, que atende em período integral a crianças da Krippe e do Kindergarten em agrupamentos mistos e também oferecem um serviço extraescolar denominado Hort, para crianças e jovens dos quatro aos catorze anos de idade.

Além delas, com o objetivo de ampliar o número de vagas, o governo federal alemão criou em 2004 o Kindertagespflege, regulamentado pelo Sozialgesetzbuch VIII, consiste no

\footnotetext{
${ }^{6}$ Cf. original: "Several reasons must be considered as the triggers for less frequent attendance or nursery school: firstly, these facilities are less often perceived as teaching institutions. And financial considerations keep parents from enrolling their children - especially if there are other family members who are available as carers. Finally, the fear of cultural alienation might also play a role" (SCHNEIDER, 2008).

${ }^{7}$ Cf. original: "Germany: Some Länder have abolished parental fees, either for the last year in ECEC before school entry (Hamburg, Hessen, Lower Saxony, North Rhine-Westphalia), for the last three years in kindergarten (Berlin), or from the age of 2 (Rhineland-Palatinate)" (EUROPEAN COMMISSION, 2014, p.84).
} 
credenciamento de profissionais para atuar em sua residência, ou na do tutor legal, com grupos de até cinco crianças. Para tanto, a administração municipal oferece um curso de qualificação com no mínimo 160 horas.

É dentro deste escopo e no contexto da crise dos refugiados que, em 2016, o Governo Federal lançou, através do Bundesministerium für Familie, Senioren, Frauen und Jugend (Ministério da Família, do Idoso, da Mulher e da Juventude), o Programa Frühe Chancen (Chances Precoces, em tradução livre). Destaca-se como o seu objetivo, para além da integração do migrante à sociedade alemã, a provisão das chamadas "oportunidades de vida iguais" entre alemães e não alemães, uma vez que se constatou que "as crianças de origem não alemã estão sobrerrepresentadas na Hauptschule, a escola secundária de nível mais elementar no sistema educacional alemão" (SCHNEIDER, 2008,n.p, tradução nossa) ${ }^{8}$.

Com o Frühe Chancen, o Governo Federal agrupa uma série de programas voltados à primeira infância, focalizando os imigrantes, especialmente do grupo de refugiados. Este pacote inclui o atendimento domiciliar Kindertagespflege, o qual visa expandir a oferta de educação infantil em curto prazo e a baixo custo; o Sprach Kitas, instituído para promover a integração social e a aprendizagem da língua alemã; o Kita Einstieg, que esclarece às famílias sobre as possibilidades de educação, sanando dúvidas sobre creches, jardins de infância e atendimento domiciliar, busca também mapear e ampliar a oferta, além de contribuir com a formação profissional; e o Kita Plus, que visa prolongar e flexibilizar o tempo de permanência das crianças na instituição escolar ou no atendimento domiciliar.

Deste modo, vemos que o governo federal alemão, além de abrir suas fronteiras aos refugiados (mesmo havendo posteriormente um maior controle sobre as entradas), esboça preocupação e adota medidas para a inclusão das crianças refugiadas na educação infantil, com vistas a promover tanto a inserção social como também facilitar a aquisição do idioma, sem o qual fica impossível de se alfabetizar.

Entretanto, para atacar o problema da inequidade educacional há que se rever o sistema educacional alemão, que destina as crianças muito cedo para escolas que já determinam o seu futuro profissional, desconsiderando os diferentes tempos de aprendizagem de cada indivíduo,

\footnotetext{
8 Cf. original: "Children from non-German families are strongly over-represented in special schools and the Hauptschule type of secondary modern school" (SCHNEIDER, 2008).
} 
que, no caso do imigrante, encontra a língua como uma barreira que leva um pouco mais de tempo a ser transposta.

Com o discurso de conferir oportunidades iguais a todos, a aposta na educação infantil é válida, benéfica, porém sem garantias, já que outros fatores como as condições de vida da família, o acesso à escolarização dos pais, o interesse pela leitura, etc. também surtem efeito sobre o sucesso ou fracasso escolar e são problemas que não têm sido enfrentados. Quais são as condições em que vivem as crianças em abrigos de refugiados? Qual é a qualidade de vida que ela tem nesses locais e que acesso ela tem a recursos educacionais ou mesmo a brinquedos para que possam viver a infância plenamente? Estes fatores são tão importantes quanto a aprendizagem do idioma alemão para tornar as oportunidades entre alemães, migrantes e refugiados menos desiguais, se não, logo as avaliações apontarão para uma subcategoria de migrantes fadados ao insucesso e evasão escolar: os refugiados.

\section{Considerações finais}

Ainda estamos distantes de viver em um mundo sem fronteiras e, mesmo em casos de calamidade, como a guerra da Síria, que já perdura há mais de seis anos, verificar que pedidos de refúgio têm sido negados, fere os direitos humanos numa violência tão cruel quanto a dos conflitos armados de onde estas pessoas fugiram.

A Alemanha adotou a política de abertura de fronteiras e, ainda que tenha recuado posteriormente, ao selar juntamente com os membros da União Europeia o acordo sobre o regresso de refugiados à Turquia, implementou um programa federal na área da educação, denominado Frühe Chancen, com a perspectiva de acolhimento das crianças, de integração social e de promover oportunidades educacionais iguais entre alemães e não alemães, encarando um problema apontado desde a década passada e que custa ser superado.

Traçamos ressalvas a respeito desta política e acreditamos que oportunidades mais igualitárias não se restringem ao acesso e permanência da criança na escola, pois também se deve promover o desenvolvimento integral da criança, tanto no âmbito institucional, como no seio familiar. 


\section{Referências}

ALEMANHA. Kinder- und jugendhilfegestz. Altera o SGB VIII. Disponível em: https://www.gesetze-im-internet.de/kjhg/KJHG.pdf. Acesso: 05 jul. 2016.

ALEMANHA. Sozialgesetzbuch. Achtes Buch (VIII) Kinder- und Jugendhilfe. Dispõe sobre os direitos da criança e do adolescente. Disponível em: https://www3.arbeitsagentur.de/web/wcm/idc/groups/public/documents/webdatei/mdaw/m tiw/ edisp/I6019022dstbai381735.pdf?_ba.sid=L6019022DSTBAI381738 Acesso: 05 jul. 2016.

BERTRAM, H. Overview of child well being in Germany: policy towards a supportive environment for children. Unicef, 2006, ISSN: 1014-7837. Disponível em: https://www.unicefirc.org/publications/465/. Acesso: 26 jul. 2016.

EUROPEAN COMISSION /EACEA/ EUROSTAT. Key data on early childhood education and care in Europe: relatório Eurydice e Eurostat. Luxemburgo: Publications Office of the European Union, 2014. ISBN 978-92-9201-567-1. Disponível em: https://publications.europa.eu/en/publicationdetail/-/publication/4bda53c1-7352-11e5-86db-01aa75ed71a1/language-en. Acesso: 02 ago. 2018.

GODOY, P. L. As políticas para a educação infantil no Brasil e Alemanha: reflexões a partir do diálogo com as políticas emanadas pelos organismos multilaterais. 2017. 107f. Trabalho de Conclusão de Curso (Bacharel em Pedagogia) - Universidade Estadual de Campinas, Campinas, 2017.

ONU. Declaração Universal dos Direitos Humanos. Disponível em:

http://www.direitoshumanos.usp.br/index.php/Declara\%C3\%A7\%C3\%A3o-Universal-dosDireitos-Humanos/declaracao-universal-dos-direitos-humanos.html. Acesso em 24 out. 2016.

PORTELA, E. A.; SCHWINN, S. A. Elementos para (re)pensar a mobilidade humana: globalização, novos fluxos migratórios e políticas públicas. In: BAENINGER, R. et al (Orgs.). Migrações sul-sul. Campinas: NEPO, 2018, p.700-711.

RAMOS, A. C. Asilo e refúgio: semelhanças, diferenças e perspectivas. In: RAMOS, A. C.; RODRIGUES, G.; ALMEIRA, G. A. (Orgs). 60 anos de Acnur: perspectivas de Futuro. São Paulo: CL-A Cultural, 2011, p.15-44.

RIJO, D. F. R. A União Europeia face à crise dos migrantes e refugiados: um ator dividido sob escrutínio. 2017, 204f. Dissertação (Mestrado em Relações Internacionais) - Universidade do Minho, Braga, Portugal, 2017.

SALOMÃO, W. F. A proteção internacional do indivíduo pelos direitos humanos: a crise dos refugiados na União Europeia. Themis, v.15, n.1. p.197-215, 2017. Disponível em: http://revistathemis.tjce.jus.br/index.php/THEMIS/article/view/552. Acesso: 10 jun. 2018. 
SCHNEIDER, C. Unicef report on the situation of children in Germany. München: Verlag C.H. Beck, 2008. ISBN: 9783406548 280. Disponível em: http://themajugend.de/fileadmin/PDF/ThemaJugend2008-3.pdf. Acesso 12 mai.2016.

UNICEF. Convenção sobre os direitos da criança. Disponível em:

https://www.unicef.org/brazil/convencao-sobre-os-direitos-da-crianca. Acesso: 11 jun. 2019.

VEDOVATO, L. R. O direito de ingresso do estrangeiro. 1. ed. São Paulo: Editora Atlas, 2013. Ebook. ISBN 978-85-224-7493-6. Disponível em: https://www.grupogen.com.br/e-book-odireito-de-ingresso-do-estrangeiro. Acesso: 16 jun.2019.

Recebido em agosto de 2018.

Aprovado em maio de 2019. 